\title{
Effects of Accelerated Carbonation on Physical Properties of Mortar
}

\author{
Kipyo You ${ }^{1}$, Hyoseok Jeong ${ }^{2}$ and Wongil Hyung $*^{3}$ \\ ${ }^{1}$ Professor, Department of Architectural Engineering, Jeonbuk National University, Korea \\ ${ }^{2}$ Researcher, The Korea Occupational Safety and Health Agency (KOSHA), Korea \\ ${ }^{3}$ Professor, School of Architecture, Yeungnam University, Korea
}

\begin{abstract}
Carbonation has been considered as a deterioration factor in concrete because it reduces the $\mathrm{pH}$ of concrete from between 12.6 and 13.5 to about 9. However, carbonation can have some positive consequences. Because $\mathrm{CaCO}_{3}$ occupies a greater volume than $\mathrm{Ca}(\mathrm{OH})_{2}$, which it replaces, the porosity of carbonated concrete decreases. On the other hand, carbonation turns bound chloride into free chloride. The results verify that carbonation has some beneficial effects by enhancing compressive strength and volume safety and reducing permeability and chloride ion penetration. In general, carbonation enhances concrete performance.
\end{abstract}

Keywords: carbonation; deterioration factor; permeability

\section{Introduction}

Reinforced concrete is a highly durable composite material made with concrete and steel. Here steel supplements insufficient mechanical characteristics of concrete, and concrete prevents steel corrosion. Reinforcing bars supplement the low tensile strength of concrete, and the passive film 20 to $60 \AA$ thick formed by highly alkaline concrete $(\mathrm{pH} 12.5-13)$ prevents the corrosion of normal concrete. However, if the passive film is broken for any reason such as construction problems and physical or chemical factors, then the steel starts to corrode, reducing performance through the deterioration of steel adhesion, the spallation of the concrete covering, and the deterioration of moment resistance caused by a decrease in the cross section of the reinforcement, among others. Among such diverse causes, carbonation and salt damage are generally the main causes of steel corrosion in reinforced concrete. Carbonation is a phenomenon in which there is corrosion in the reinforcement because the passive film on the reinforcement is not protected from $\mathrm{CO}_{2}$, which exists in the air at about $0.03 \%,{ }^{1}$ because of the low $\mathrm{pH}$ of concrete $(\mathrm{pH} 8.5-10)$. Carbonation is one of the most important causes of a deterioration in reinforced concrete in terms of its durability and thus has received considerable research attention. Carbonation progresses from the concrete surface to the inside, and

*Contact Author: Wongil Hyung, Professor,

School of Architecture, Yeungnam University,

Dae-dong, Gyeongsan, 712-749, Korea

Tel: +82-53-810-2597 Fax: +82-53-810-4625

E-mail: beda@yu.ac.kr

(Received April 11, 2013 ; accepted November 11, 2013) the concrete becomes heavier and denser in proportion to the weight of its reaction with the carbonic acid gas. Minute cracks appear on reinforced concrete in the process of carbonation, although they are too small to be a problem. The biggest problem with respect to the deterioration of the physical performance of reinforced concrete from the carbonation phenomenon is the corrosion of concrete reinforcements. ${ }^{2-4}$ The calcium carbonate created by carbonation fills inner pores of the reinforced concrete and makes its structure denser, reducing the rate of increase in its carbonation depth and thus improving its acid resistance and strength and reducing its permeability. ${ }^{5}$ Several studies have examined this phenomenon and suggested the necessity of using carbonation as an application factor instead of as a performance deterioration factor. Most studies have addressed the suppression of carbonation by focusing on the carbonation mechanism, the life of concrete with carbonation, and the carbonation speed, but this paper examines the effect of carbonation on cement mortar's strength, permeability, pore structure, and resistance to chloride penetration through a test based on accelerated carbonation to determine the physiochemical characteristics of the carbonated cement hydrate.

\section{Experiment \\ 2.1 Materials and Mix Proportions \\ 1) Cement and fine aggregate}

Ordinary Portland cement specified in KS(Korea Standard)-L5201 was used in all mixtures. Siliceous sand(sizes: $0.25-0.6 \mathrm{~mm}$ ) specified in KS-L5100 was in the form of fine aggregate. 
Table 1. Chemical Composition and Physical Properties of Ordinary Portland Cement

\begin{tabular}{|c|c|c|c|c|c|c|c|c|}
\hline \multirow{2}{*}{$\begin{array}{c}\text { Chemical } \\
\text { composition(\%) }\end{array}$} & $\mathrm{SiO}_{2}$ & $\mathrm{Al}_{2} \mathrm{O}_{3}$ & $\mathrm{Fe}_{2} \mathrm{O}_{3}$ & $\mathrm{CaO}$ & $\mathrm{MgO}$ & $\mathrm{SO}_{3}$ & \multicolumn{2}{|c|}{ Ig.loss } \\
\hline & 20.57 & 5.48 & 3.18 & 63.03 & 3.41 & 2.23 & & \\
\hline \multirow{3}{*}{ Physical properties } & Density & \multirow{2}{*}{\multicolumn{2}{|c|}{$\begin{array}{l}\text { Blaine's specific surface } \\
\text { area }\left(\mathrm{cm}^{2} / \mathrm{g}\right)\end{array}$}} & \multirow{2}{*}{\multicolumn{2}{|c|}{$\begin{array}{l}\text { Setting time } \\
\text { (h-min) }\end{array}$}} & \multicolumn{3}{|c|}{ Compressive strength } \\
\hline & $\left(20^{\circ} \mathrm{C}\right.$ & & & & & $3 d$ & $7 \mathrm{~d}$ & $28 \mathrm{~d}$ \\
\hline & 3.15 & & & $5-7$ & $7-20$ & 194 & 216 & 323 \\
\hline
\end{tabular}

Table 2. Properties of Fine Aggregate

\begin{tabular}{ccccc}
\hline Size $(\mathrm{mm})$ & Fineness modulus & Unit weight $(\mathrm{kg} / \ell)$ & Density $\left(20^{\circ} \mathrm{C}\right)$ & Water content $(\%)$ \\
\hline$<0.6$ & 2.47 & 1.5 & 2.65 & 0.40 \\
\hline
\end{tabular}

\section{2) Manufacture and Curing of the Test Piece}

The water-cement mixing ratio was $55 \%$, and the cement-sand mixing ratio was $1: 2$. The test specimens were manufactured using a $\varphi 100 \times 200 \mathrm{~mm}$ circular mold to measure the carbonation depth, chloride penetration, and the pore volume and to conduct permeability and penetration tests, the X-ray diffraction test, and SEM. To examine accelerated carbonation, the surroundings of each specimen other than both cross sections were painted with epoxy so that the carbonic acid gas could penetrate only these cross sections. The specimen used to test the compressive strength of reinforced concrete was manufactured using a $50 \times 50 \times 50 \mathrm{~mm}$ mold, and that used to test the chloride penetration depth by immersing it in a chloride solution and observing the penetration of the chloride ion was manufactured using a $60 \times 60 \times 60 \mathrm{~mm}$ mold. All test specimens were cured in water 24 hours after their formation for 27 days at $20 \pm 2^{\circ} \mathrm{C}$.

\subsection{Experimental Methods}

\section{1) Accelerated Carbonation Depth}

For the accelerated-carbonation test, the test specimen cured for 28 days was stored in a carbonation accelerator (temperature: $25^{\circ} \mathrm{C}$; relative humidity: $40 \% ; \mathrm{CO}_{2}$ concentration: $15 \%$ ) for 14 days. Then it was divided equally into two parts, and the part that did not turn red when $1 \%$ phenolphthalein solution was sprayed on its cross section was used to measure the carbonation depth.

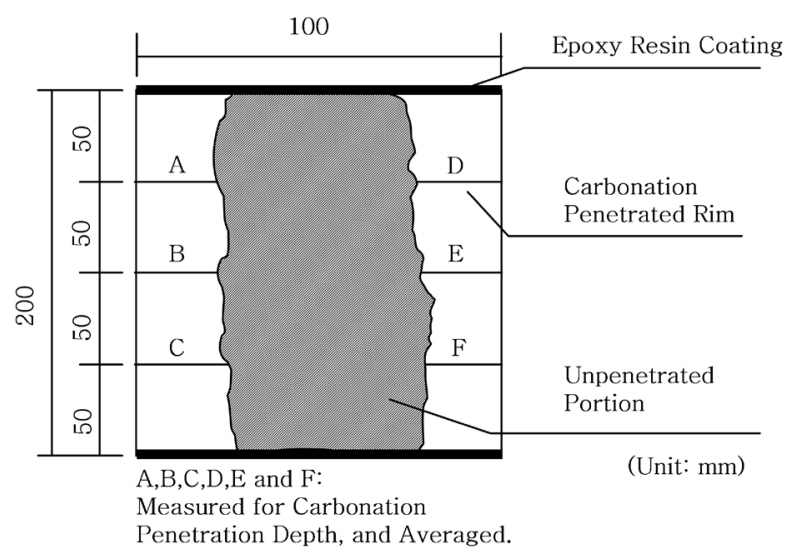

Fig.1. Cross Section of the Specimen after the Carbonation Test

\section{2) Compressive Strength}

The compressive strength of mortar was tested according to KS L 5105 (testing method for the compressive strength of cement mortar) with $50 \times 50 \times 50 \mathrm{~mm}$ test specimens.

\section{3) Water Absorption}

Cured beam specimens were immersed in water at $20^{\circ} \mathrm{C}$ for 48 hours, and their water absorption was determined in accordance with KS F 4916.

\section{4) Chloride Ion Penetration Test}

Chloride ion penetrability was measured using a tester manufactured in a manner similar to that for Whiting's coulomb tester. ${ }^{6}$ The test was based on ASTM C 1202-91 (electrical indication of concrete's ability to resist chloride ion penetration $)^{7}$ and AASHTOT 277- 831 (rapid determination of the chloride permeability of concrete) ${ }^{8}$ as follows: From the $100 \times 50 \mathrm{~mm}$ test specimen, the current flowing through the mortar was measured at 30 -minute intervals for 6 hours according to the carbonation depth. The total charge passing through the specimen was calculated using the following equation:

$\mathrm{Q}=900\left(\mathrm{I}_{0}+\mathrm{I}_{30}+\mathrm{I}_{60}+---+\mathrm{I}_{300}+\mathrm{I}_{330}+\mathrm{I}_{360}\right)$, where $\left(\mathrm{Q}=\right.$ total charge; $\mathrm{I}_{0}=$ initial current; $\mathrm{I}_{\mathrm{t}}=$ current at time $\mathrm{t}$ ).

\section{5) Powder X-Ray Diffraction Test and Electron Microscopy}

To examine the change in the hydrated cement of the test specimen carbonated in the carbonation accelerator, the parts of the identical test specimen exposed to accelerated carbonation for 6 weeks, which were colored or non-colored by phenolphthalein solution, were obtained and tested with a powder X-ray diffractometer (Rigaku, Max/III-A, Japan) and an electron microscope.

\section{6) Pore Volume}

To measure the pore structure, a specimen was obtained from inside the $40 \times 40 \times 160 \mathrm{~mm}$ test specimen and subjected to D-dry treatment. The pore volume was measured using a mercury intrusion porosimeter to calculate the total pore volume. 


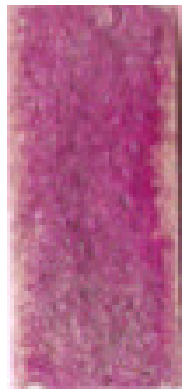

(a) 1 week

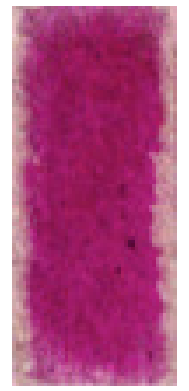

(b) 2 week

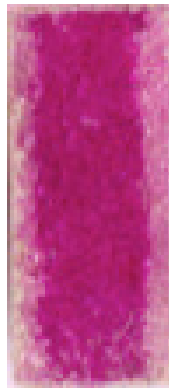

(c) 4 week

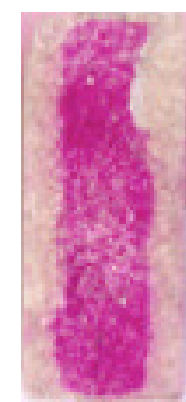

(d) 6 week
Photo 1. Carbonation Depth of Specimens by Carbonation Period

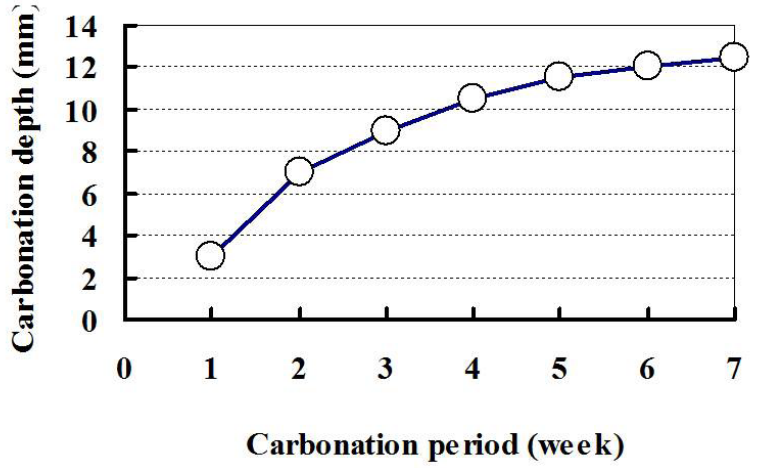

Fig.2. Carbonation Depth vs. Period

\section{Results and Discussion}

\subsection{Carbonation Depth}

Fig.2. shows the carbonation depth according to the carbonation period. The carbonation depth increased with an increase in the carbonation period, but its rate of increase decreased. Previous studies have found that, during the carbonation period, calcium carbonate is produced from the penetration of $\mathrm{CO}_{2}$ in the concrete, and the evaporated moisture slows the supply of $\mathrm{CO}_{2}$ inside the concrete.

\subsection{Changes in Compressive Strength}

Fig.3. shows the change in compressive strength over the carbonation period. The carbonated test specimen was stronger than that not carbonated for the same period, which was within the $6-1.5 \%$ range. This result is consistent with the findings of previous studies. Compressive strength increased because carbonation produced a denser structure. However, there was no proportionate correlation in which the carbonation depth increased with an increase in compressive strength. This may be explained by a decrease in compressive strength as a result of the decomposition of hydrates, including C-S-H, in conjunction with an increase in the strength from a decrease in the pore volume. ${ }^{9}$

\subsection{Changes in the Absorption Rate over the Carbonation Period}

Fig.4. shows the change in the water absorption rate over the carbonation period. The absorption rate decreased with the carbonation period, and the highest rate of decrease was observed in the initial

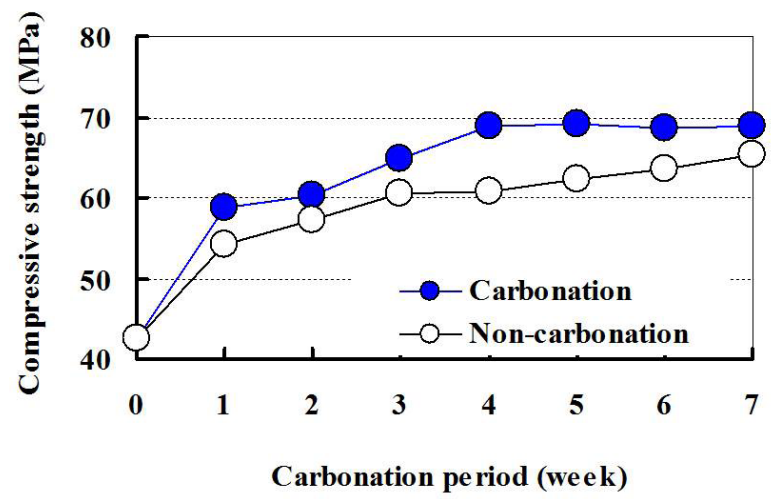

Fig.3. Compressive Strength of Carbonated and Non-Carbonated Specimens vs. the Carbonation Period

one-week carbonation period, after which there were no significant changes. The volume stabilized against the absorption rate because of the dense structure. ${ }^{10}$ According to previous research, carbonated cement materials alternately dried and humidified are half as long as un-carbonated ones. ${ }^{11}$ A larger decrease in the absorption rate was observed in the first week of carbonation, but there was very little effect on the decrease in the absorption rate in other periods. This may be explained by the effect of the structure that became denser over the one-week carbonation period.

\subsection{Change in the Chloride Ion Penetration} According to the Carbonation Period

Fig.5. shows the current caused by chloride ions passing through the test specimen at 30 -minute intervals, and Fig.6. shows the quantity of their charge. As shown in Fig.5., the current passing through the test specimen as well as the quantity of the charge decreased as the carbonation progressed. The current decreased because of denser pores in mortar caused by carbonation. Accordingly, the inner structure became denser from carbonation and strongly resisted the penetration of chloride ions. However, this was an indirect experimental method designed to facilitate a comparison, and therefore it was not possible to determine the degree of chloride ion penetrability. In addition, the correlation between specific ions $\left(\mathrm{Cl}^{-}\right)$and the total charge was difficult to determine because the total charge was related to the behavior of all ions (including $\mathrm{Na}^{+}, \mathrm{K}^{+}, \mathrm{Ca}^{2+}$, and $\mathrm{OH}^{-}$) in the pore solution. ${ }^{12}$ In addition, such an electrical method requires humidity inside, but the absorption rate decreased in part from carbonation. These results demonstrate the effect of calcium hydroxide filling by carbonation near surface pores. ${ }^{13}$

\subsection{Powder X-Ray Diffraction Test}

Fig.7. shows the results of the powder X-ray diffraction test. Among cement hydrates, strong alkali calcium hydroxide $(\mathrm{pH} 12-13)$ reacts to the $\mathrm{CO}_{2}$ fed through the capillary pores and generates calcium carbonate. The powder X-ray test that was performed to verify the process showed that calcium carbonate was generated on the carbonated parts, whereas 


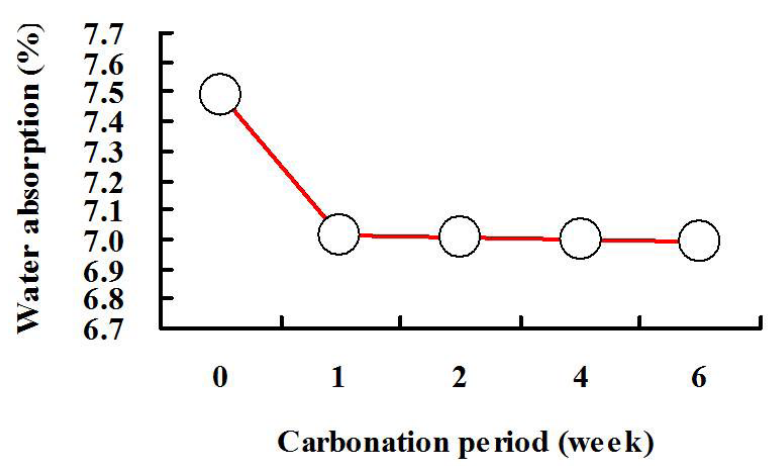

Fig.4. Relationship Between Water Absorption and the Carbonation Period

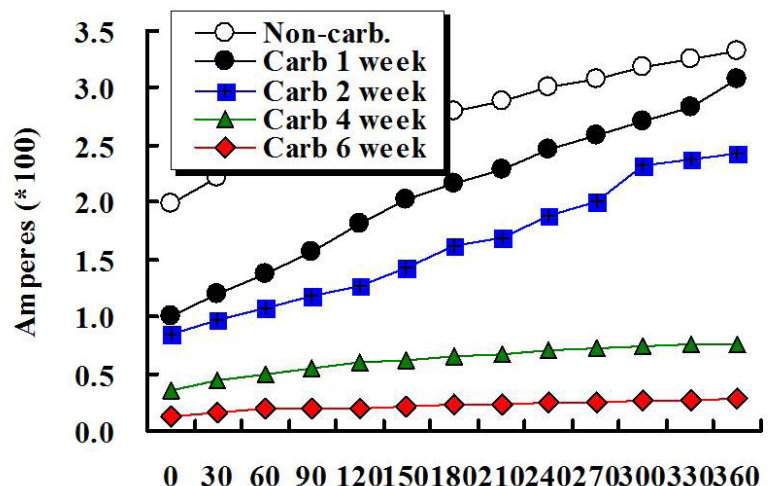

Time (minute)

Fig.5. Relationship Between the Passing Current and the Carbonation Period Recorded Every 30 min. Over a 6-hour Period

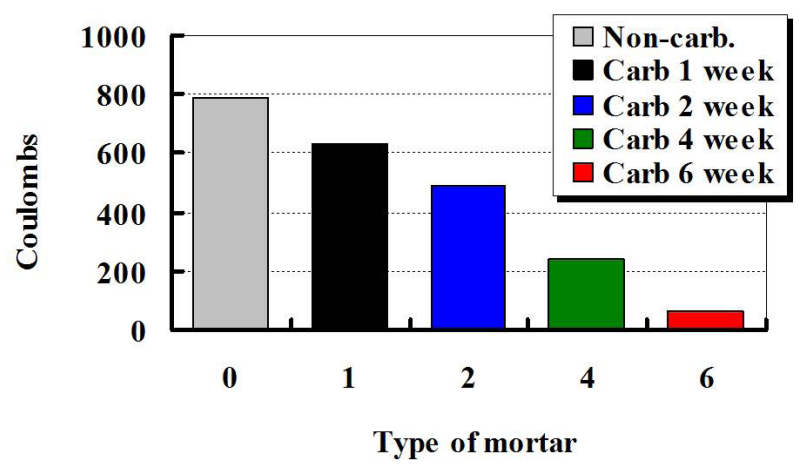

Fig.6. Total Charge (in Coulombs) Passing Through the Specimen After 6 Hours by Carbonation Period

calcium hydroxide decreased. The upper part was the result of the pulverization of the test specimen obtained from the un-carbonated part in the X-ray diffraction test. Unique calcium hydroxide and calcium carbonate peaks appeared in the test specimen from the un-carbonated part, whereas different calcium hydroxide and calcium carbonate peaks appeared in the test specimen from the carbonated part (below). The calcium hydroxide in the carbonated test specimen turned into calcium carbonate, and calcium carbonate was also observed in the un-carbonated part due to the penetration of $\mathrm{CO}_{2}$. There was more calcium carbonate than calcium hydroxide at the boundary between the un-carbonated part and the carbonated part of the test specimen, and there was some calcium carbonate inside the boundary surface.

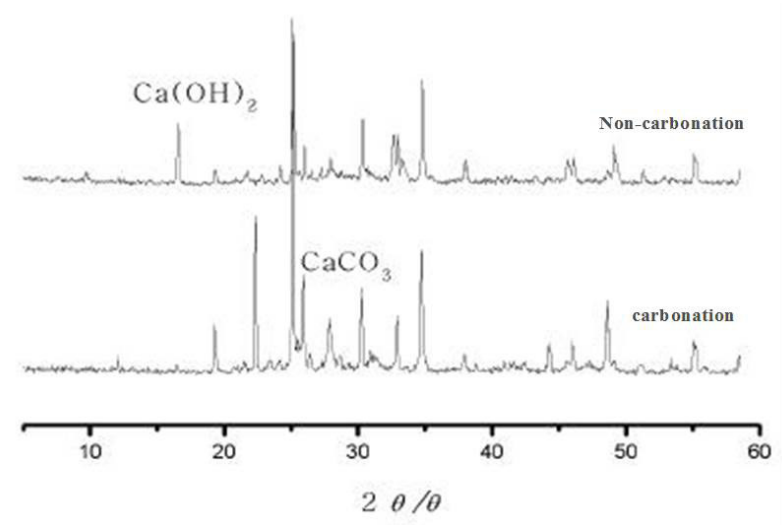

Fig.7. Powder X-ray Diffraction Test

\subsection{Electron Microscopy}

Photo 2. shows the electron microscopy of cement microstructures before and after carbonation. Cement hydrates as well as calcium hydroxide changed because of $\mathrm{CO}_{2}$. In the carbonated part, as shown in Photo 2.(a), only unique bulk-type structures were observed, and there was no spicule-style ettringite. This indicates that the ettringite also changed from carbonation. That is, calcium hydroxide precipitated as calcium carbonate as a result of the penetration of $\mathrm{CO}_{2}$, and its $\mathrm{pH}$ decreased. However, other cement hydrates were also carbonated as a result of $\mathrm{CO}_{2}$.

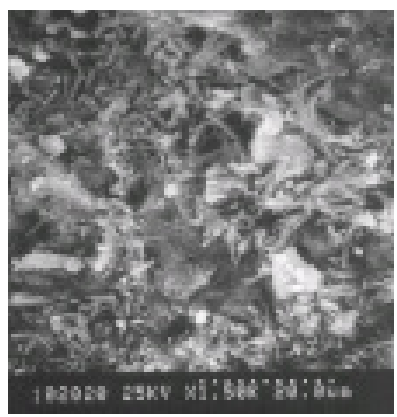

(a) Non-carbonation

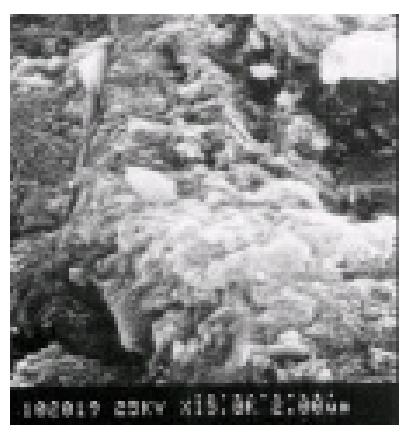

(b) Carbonation
Photo 2. Microstructure of Non-Carbonated and Carbonated Mortar by SEM

\subsection{Pore Size and Volume}

Fig.8. shows the pore size and total pore volume of the un-carbonated and carbonated test specimens. The carbonated test specimen had fewer pores than the uncarbonated one. Capillary pores (which had diameters of 0.01-0.1 $\mu \mathrm{m}$ and had important effects on chloride penetration) decreased by about $74 \%$ in the carbonated specimen. Pores with diameters exceeding $0.1 \mu \mathrm{m}$ also decreased, highlighting the important role played by carbonation in reducing chloride ion penetrability. 
Pores with diameters less than $0.01 \mu \mathrm{m}$ were observed more frequently in the carbonated specimen, although they had no significant effect on chloride ion penetrability. These results can be explained by the pore filling of calcium carbonate as a result of carbonation. This suggests that accelerated carbonation can effectively prevent the formation of hazardous materials on the surface of concrete mortar.

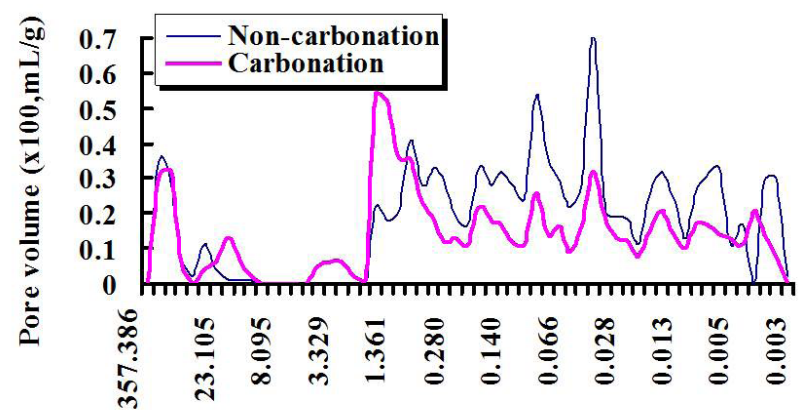

Pore radius $(\mu \mathrm{m})$

(a) Pore Volume vs. Pore Radius of Non-Carbonated and Carbonated Mortar

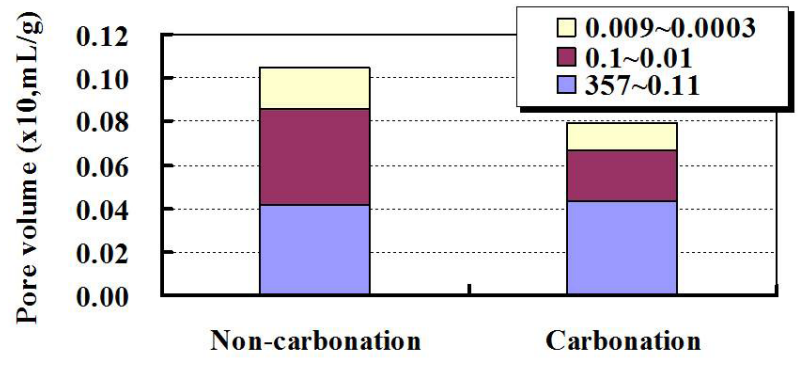

Carbonation status

(b) Pore Volume vs. Size

Fig.8. Total Pore Volume of Test Specimens

\section{Conclusion}

The effects of carbonation on physical characteristics of cement mortar evaluated through a test based on accelerated carbonation can be summarized as follows:

1. The carbonation depth increased with the period of carbonation, but its rate of increase decreased because the small amount of calcium carbonate generated by carbonation filled mortar pores and limited the supply of $\mathrm{CO}_{2}$ required for carbonation.

2 . In the test of compressive strength under the same curing, the carbonated specimen showed greater compressive strength than the un-carbonated specimen because of the filling effect of calcium carbonate. However, carbonation progressed over the period of carbonation, and compressive strength showed no continuous increases.
3. In the test of chloride ion penetration, the test specimen with accelerated carbonation showed much greater resistance to chloride ion penetration than that without.

4. In the test of the pore structure, the test specimen with accelerated carbonation showed a microstructure as a result of a decrease in its total pore volume.

5. In sum, cement mortar with accelerated carbonation showed excellent compressive strength, resistance to chloride penetration, and pore reduction effects. This suggests that accelerated carbonation can enhance the performance of cement mortar.

\section{Acknowledgement}

This work was supported by the 2011 Yeungnam University Research Grant.

\section{References}

1) M. Sakuta et al., Measures to restrain rate of carbonation in concrete, in Concrete Durability, Vol.2, ACI SP - 100, pp.19631977 (Detroit, Michigan, 1987).

2) D.W.S. Ho and R.K. Lewis. The specification of concrete for reinforcement protection - performance criteria and compliance by strength, Cement and Concrete Research, Vol. 18, No. 4. pp.58494. 1988.

3) M. Castellote, C. Andrade, X. Turrillas, J. Campo, G.J. Cuello, Accelerated carbonation of cement pastes in situ monitored by neutron diffraction, Cement and Concrete Research, Vol.38, No.12, pp.1365-1373, 2008.

4) Alexander Steffens, Dieter Dinkler, Hermann Ahrens, Modeling carbonation for corrosion risk prediction of concrete structures, Cement and Concrete Research, Vol.32, No.6, pp.935-941, 2002.

5) The Concrete Society, "Permeability testing of site concrete - a review of methods and experience", Report of a Concrete Society Working Party, Permeability of Concrete and its control, Papers for a one-day Conference, London, 12 December 1985, The Concrete Society, 1985, pp.1-68.

6) Whiting, D., "Rapid determination of the chloride permeability of concrete", Washington DC, Federal Highway Administration, 1981, Report No. RD- 81/ 119.

7) Annual Book of ASTM Standard, C 1202, "Electrical indication of concrete's ability to resist chloride ion penetration", 1990.

8) Standard Specification for Transportation Materials and Methods of Sampling and Testing, Fourteenth Edition, American Association of St ate Highway and Transportation Officials (AASTHO), Washington D. C., 1986.

9) Verbeck, G., "Pore structure - Significance of tests of properties of concrete and concrete aggregates", Philadelphia, American Society for Testing and Materials 1965, ASTM Special Technical Publication No. 169, pp.136-142.

10) Properties of concrete, Fourth and Final Edition. A.M. Neville pp.498-499.

11) Joseph J. Shideler, "Investigation of the Moisture - Volume Stability of Concrete Masonry Units, "Bulletin D3, Development Dept., Portland Cement Assn., March, 1955.

12) Standard specification for Transportation Materials and Methods of Sampling and Testing, fourteenth Edition, American Association of State Highway and Transportation Officials (AASHTO), Washington D.C., 1986.

13) F. A. Sarott, M.H. Bradbury, P. Pandolfo and P. Spieler. "Diffusion and adsorption studies on hardened cement paste and the effect of carbonation on diffusionrates", Cement and Concrete Research. Vol.22, pp.439-444, 1992. 